\title{
Synthesis of Lignin-Based Polyacid in an Acidic Ionic Liquid: A Green Method to Improve the Performance of Lignin as Catalyst in Urea-Formaldehyde Resin
}

\author{
Hamed Younesi-Kordkheilii ${ }^{1, *}$ and Antonio Pizzi ${ }^{2}$ \\ ${ }^{1}$ Department of Wood and Paper Sciences, Faculty of Natural Resources, Semnan University, Semnan, Iran \\ ${ }^{2}$ LERMAB, University of Lorraine, Epinal, France \\ *Corresponding Author: Hamed Younesi-Kordkheili. Email: Hamed.Younesi@semnan.ac.ir \\ Received: 11 June 2021 Accepted: 13 July 2021
}

\begin{abstract}
The aim of this research was to investigate the effect of ionic liquid treated lignin-based polyacid as a catalyst for urea-formaldehyde (UF) resins. Esterification of lignin was carried out, without any catalyst, with anhydride maleic and 1-butyl-3-methylimidazolium hydrogen sulfate $[\mathrm{Bmim}]\left[\mathrm{HSO}_{4}\right]$ as acidic ionic liquid to form maleated lignin-based polyacids (MA-IL). The performance of MA-IL as UF resin catalyst was respectively compared to hyroxymethylated lignin-based polyacid (MA-HL) and to $\mathrm{NH}_{4} \mathrm{Cl}$. The FTIR analysis indicated that the proportion of $-\mathrm{COOH}$ and $\mathrm{C}-\mathrm{O}$ bonds increased due to the esterification of lignin with ionic liquid rather than its hyroxymethylation. Physicochemical tests indicated that the gelation time of the UF resin was shorter by adding MA-IL when compared to $\mathrm{NH}_{4} \mathrm{Cl}$ and MA-HL, respectively. DSC analysis showed that the addition of MA-IL significantly decreased the temperature peak (Tp) of the UF resin; as the Tp of the UF resin with 2 wt\% MA-IL was lower than with MA-HL and $\mathrm{NH}_{4} \mathrm{Cl}$, respectively. The panel test results of plywood bonded with a UF resin with a MA-IL level increasing from $1 \%$ to $3 \%$, effectively improved the mechanical strength, water resistance and formaldehyde emission even higher than with $\mathrm{MA}-\mathrm{HL}$ and $\mathrm{NH}_{4} \mathrm{Cl}$, respectively.
\end{abstract}

\section{KEYWORDS}

Lignin-based polyacid; maleic anhydride; ionic liquid; esterification; plywood

\section{Introduction}

Nowadays most wood-based panels in the world are bonded with urea-formaldehyde (UF) resins. UF resins start curing under acid condition in the hot press when manufacturing panels [1]. For this reason, acid based catalysts such as inorganic acids, organic acids and acidic salts have been used to create suitable conditions for UF resins curing. Previous studies indicated that the acid-releasing salts such as $\mathrm{NH}_{4} \mathrm{Cl}$ exhibited better properties compared to other types of catalysts as they are inexpensive, effective, without annoying byproducts and easy to use [2]. Ionic liquid, $\mathrm{H}_{2} \mathrm{SO}_{4}, \mathrm{HCl}, \mathrm{H}_{3} \mathrm{PO}_{4}$, and $\mathrm{NaOH} / \mathrm{NH}_{4} \mathrm{OH}$ are the other types of catalysis which were used in UF resin. However the use of this catalysis did not growing due to economic reasons and their lower performance compared to $\mathrm{NH}_{4} \mathrm{Cl}$ [3]. As well adapt to the task $\mathrm{NH}_{4} \mathrm{Cl}$ is as an amino resin hardener, some drawbacks of its use are clearly present: (I) $\mathrm{NH}_{4} \mathrm{Cl}$ hydrolysis during hot-curing produces a number of open cavity blisters in the hardened resin due to ammonia gas being emitted, causing a resin strength decrease at the interface, hence of the bonded wood 
panel; (II) the toxic chlorine $(\mathrm{Cl})$ is a environmental polluting chemical, in particular in the "greening" of a UF adhesive; (III) the acid residues left by the acid hardener in the resin may additionally degrade bioh the hardened adhesive and hydrolyse the wood carbohydrates at the panels resin/wood interface with some marked degradation [2,4]. Previous research work indicated that organic molecules exhibited good results as catalyst for thermoset resins [5], as small organic molecules catalysts can be vaporized during hot pressing. Thus, grafting of organic acid to macromolecules such as lignin as a new catalyst for UF resins has been proposed in previous research works [6,7]. In this method, an organic acid-yielding material such as maleic anhydride is reacted with the lignin macromolecule to produce polyacids. Although the use of lignin molecules as raw material to prepare polyacids has several advantages, nonetheless the number of potentially reactive sites available on the lignin phenyl propane units is low. Hence, the lignin molecules need to be modified to increase their reactivity before any other reaction such as hydroxymethylation and phenolation [8,9]. Moreover, chemical solvents and catalysts to prepare ligninbased polyacids, such DMSO and 1-methylimidazole have high cost. Previous studies showed that the mechanical strength of plywood panels bonded with UF resins catalyzed by maleic anhydridehydroxymethylated lignin (MA-HL) is lower than that with $\mathrm{NH}_{4} \mathrm{Cl}$ as a control catalyst [6]. Thus, the aim of the present work was the synthesis of lignin-based polyacids by a green method to yield higher quality bonding with UF resins.

Ionic liquids (ILs), are green solvents and hardeners. This is so because they are chemically and thermally stable, presenting lower vapor pressure and higher ionic conductivity [10]. Halogen free ILs are more advantageous and because they are solvent free their use satisfies the aim of a greener catalysis. Husson et al. [11] indicated that acidic ionic liquid is a good solvent for fast esterification of lignin without the need of any catalyst. Li et al. [12] too showed that ionic liquid-modification is one of the best methods to improve the reactivity of lignin. The results of their research indicated that molecular weight and polydispersity of lignin molecules decreased further after treatment by ionic liquid compared to the hydroxymethylation method. Hence, the use of ionic liquid as green solvent for preparation of polyacids from lignin not only can modify the lignin's structure but also it does not need any additional catalyst in the esterification process. Thus, the aim of the research work presented here was the ionic liquids catalyzed synthesis of lignin-based polyacids for urea-formaldehyde resins. Among different types of ionic liquids used, $[\mathrm{Bmim}]\left[\mathrm{HSO}_{4}\right]$ acidic ionic liquids has been reported as being the most effective and thus was used for this research work [13].

So far the effect of different catalysts on UF resins has been studied by several researchers $[13,14]$. However there is no information in the literature on the synthesis of lignin-based polyacid by a green method to be used as a catalyst for UF resins. Thus, the additional aim of the work presented here was to investigate the synthesis of lignin-based polyacid with ionic liquid as a catalyst for urea-formaldehyde resins and its effect on the physical and mechanical properties of the plywood panels bonded with them.

\section{Materials and Methods}

\subsection{Lignin}

Bagasse Soda black liquor with $\mathrm{pH}=13$ and $80 \%$ solid content as source of lignin was prepared by Pars Company (Haft Tepe, Iran). Lignin was extracted by acid sulfuric from the liquor.

\subsection{Synthesis of Ionic Liquid-Lignin Based Polyacid (MA-IL) Catalyst}

Lignin-based polyacid by ionic liquid was prepared according to a method reported by Husson et al. [11]. The lignin was lyophilized and $\left[\mathrm{Bmim}^{2}\left[\mathrm{HSO}_{4}\right]\right.$ was dried at $80^{\circ} \mathrm{C}$ under vacuum for $4 \mathrm{~h}$. Lignin and $[\mathrm{Bmim}]\left[\mathrm{HSO}_{4}\right]$ were then stored in desiccator for $48 \mathrm{~h}$ before each reaction. $300 \mathrm{mg}$ of $[\mathrm{Bmim}]\left[\mathrm{HSO}_{4}\right]$ (melting point $28^{\circ} \mathrm{C}$ ) were incubated at $75^{\circ} \mathrm{C}$ under vigorous stirring until total liquefaction. Reaction was initiated by introducing lignin $(10 \mathrm{mg})$ and maleic anhydride in the ratio: 1/5 (w/w) and was performed at 
$75^{\circ} \mathrm{C}$ for $4 \mathrm{~h}$ under vigorous stirring. After this duration, the mixture was cooled down in an ice bath in order to stop the reaction. Acetonitrile was added in the reaction medium to precipitate the modified lignin. The resulted solid residue was collected by vacuum filtration, thoroughly washed with acetonitrile to eliminate unreacted maleic anhydride and $[\mathrm{Bmim}]\left[\mathrm{HSO}_{4}\right]$, allowing to check that there is no residual IL, and then dried for $4 \mathrm{~h}$ at $100^{\circ} \mathrm{C}$.

\subsection{Hydroxymethylation of Lignin}

Lignin Hydroxymethylation was performed by reaction with glyoxal [15]. Lignin powder (295 parts by mass, $96 \%$ solid) was slowly added to 476.5 parts water, and sodium hydroxide solution (30\%) was added from time to time to keep the $\mathrm{pH}$ of the solution between 12 and 12.5 for better dissolution of the lignin powder; this was also facilitated by vigorous stirring. A total of 141 parts by mass of sodium hydroxide solution (30\%) was added, which resulted in a final $\mathrm{pH}$ close to 12.5 . A $250 \mathrm{ml}$ flat bottom flask equipped with a condenser, thermometer and magnetic stirrer bar was charged with the previous solution and heated to $58^{\circ} \mathrm{C}$. Glyoxal ( 175 parts by mass, $40 \%$ in water) was added, and the lignin solution was then continuously stirred with a magnetic stirrer/hot plate for $8 \mathrm{~h}$.

\subsection{Synthesis of Hydroxymethylated Lignin-Based Polyacids (MA-HL) Hardeners}

Glyoxalated Lignin-based polyacids were synthesized as reported by Gao et al. [5]. First, $15 \mathrm{~g}$ constant weight Hydroxymethylated lignin was dissolved with DMSO $(50 \mathrm{~mL})$ in a four-necked flask fitted with a mechanical stirrer and is flux condenser. As a catalyst for the esterification reaction $200 \mu \mathrm{L}$ 1-methylimidazole was added drop wise to the lignin solution, and $20 \mathrm{~g}$ maleic anhydride was immediately introduced into the reaction system. Subsequently, the suspension was heated to $80^{\circ} \mathrm{C}$ and stirred continuously for $3 \mathrm{~h}$. After that, the solution was cooled down and precipitated at $\mathrm{pH} 3$ in order to recover the maleated lignin. The solid was continuously washed with water to remove the unreacted maleic anhydride. Finally, the residual solids were dried in an oven at $60^{\circ} \mathrm{C}$. The maleated Lignins were named as MA-HL.

\subsection{FTIR Analysis}

Structural changes in hydroxymethylathed and IL-treated lignin were determined by Fourier Transform Infrared spectrometry (FTIR). The lignins were oven-dried and then reduced to powder by milling before testing by FTIR. FTIR spectra were obtained from potassium bromide $(\mathrm{KBr})$ pellets with $1 \%$ of the powdered lignins at wave numbers between 400 and $4000 \mathrm{~cm}^{-1}$.

\subsection{Addition of Catalysts to UF Resin}

Different proportions of MA-HL and MA-IL $(0,1,2,3 \mathrm{wt} \%)$ were added to prepare the UF resin at room temperature. Also UF resin containing $2 \mathrm{wt} \% \mathrm{NH}_{4} \mathrm{Cl}$ (10\% solution) was prepared as a control sample. These resins were then immediately used to prepare the wood panels.

\subsection{DSC Analysis}

The curing process of UF resin with MA-IL, MA-HL and $\mathrm{NH}_{4} \mathrm{Cl}$ were tested by DSC with a NETZSCH DSC $200 \mathrm{~F} 3$ Model thermal analyzer at a heating rate of $10{ }^{\circ} \mathrm{C} / \mathrm{min}$ under nitrogen atmosphere with a flow rate of $60 \mathrm{ml} / \mathrm{min}$.

\subsection{Physicochemical Tests}

The $\mathrm{pH}$ value of the prepared resins at ambient temperature was determined with a Hanna $\mathrm{pH}$ meter (Limena, Italy). After calibration, $200 \mathrm{~g}$ of a UF sample was pipetted into a $250-\mathrm{mL}$ beaker, and the initial $\mathrm{pH}$ values of the resin and the solution, adjusted by the gradual addition of MA-HL and MA-IL from $0 \%$ to $3 \%$ (solids on solids), were recorded as ambient $\mathrm{pH}$ after 5 min of magnetic stirring at $20^{\circ} \mathrm{C}$. 
To determine the gel time, $5 \mathrm{~g}$ of the resin were introduced into a dry glass beaker. The beaker was then immersed into boiling water and the time until hardening was measured. The viscosity of synthesized resins also was determined by Ford Cup. Three replicas per sample were tested.

\subsection{Plywood Manufacturing}

$240 \mathrm{~mm} \times 200 \mathrm{~mm} \times 2 \mathrm{~mm}$ Beech (Fagus orientalis) veneers were prepared and dried to a moisture content of less than $6 \%$ by mass for manufacturing three-plys plywood. The middle veneer was spread with $250 \mathrm{~g} / \mathrm{m}^{2} \mathrm{dgl}$ (double glue line) of gluemix. The three plys were cross-assembled and hot-pressed at $160^{\circ} \mathrm{C}$ at a maximum pressure of $1 \mathrm{MPa}$ for $5 \mathrm{~min}$. Three panels were prepared for each resin. Preparation of the samples for shear strength and water absorption measurement was started $24 \mathrm{~h}$ after pressing.

\subsection{Panel Testing}

Shear specimens and water absorption tests were performed according to the ASTM D 906-98 and ASTM D4442-07 standards, respectively. The subsequent formaldehyde emission from the plywood panels was determined by using the flask method according EN 717-3 with the panel edges being left open. Five specimens were tested for each resin in all tests.

\section{Results and Discussion}

\subsection{FTIR Spectroscopy}

The infrared spectra obtained from Hydroxymethylated lignin and lignin treated with ionic liquid gave the FTIR spectra shown in Fig. 1 and Tab. 1 reports the relative interpretation assignements. The O-H stretching band at $3390 \mathrm{~cm}^{-1}$ in the IL-treated lignin is higher than for the hydroxymethylated lignin. This is due to the proportion of lignin's aliphatic and phenolic hydroxyl groups being higher due to the IL treatment. Qu et al. [16] showed that ionic liquids could preserve the phenolic hydroxyl and carboxyl groups. This increases lignin reactivity in the subsequent conversion process. Also, compared to hydroxymethylated lignin, the $3050 \mathrm{~cm}^{-1}$ band related to the $-\mathrm{COOH}$ is lower than for the IL-treated lignin. Equally, the $\mathrm{C}-\mathrm{O}$ bond at $1330 \mathrm{~cm}^{-1}$ from the esterification reaction between hydroxyl groups and maleic anhydride in the IL-treated lignin is higher than for hydroxymethylated lignin. The IL treated lignin samples displayed a significantly reduced $1700 \mathrm{~cm}^{-1}$ peak absorption compared to hydroxymethylated lignin. This may be related to the cleaved or isomerized carbonyl group or ester bonds of the sample during the treatment [17].

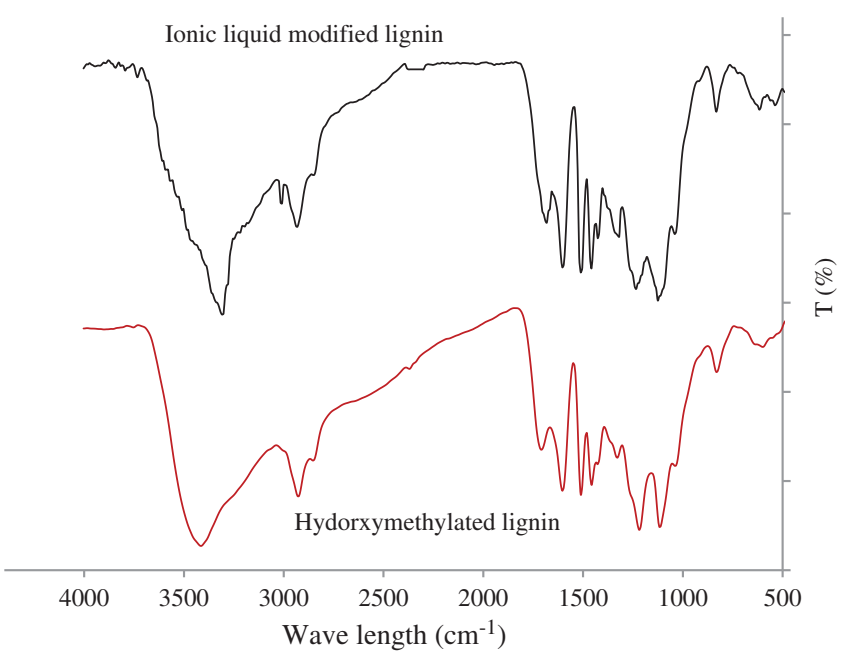

Figure 1: FTIR analysis of ionic liquid and hydorxymethylated lignin 
Table 1: FTIR assignment of lignin [18]

\begin{tabular}{ll}
\hline Assignment & Bond position $\left(\mathrm{cm}^{-1}\right)$ \\
\hline O-H stretching & 3421 \\
C-H stretching & 2937 \\
C-H stretching & 2840 \\
C=O stretching & 1682 \\
Aromatic skeletal vibration + C=O stretching & 1603 \\
Aromatic skeletal vibration & 1514 \\
C-H deformation & 1462 \\
C-H in-plane deformation with aromatic ring stretching & 1425 \\
C-O of the syringyl ring & 1327 \\
C-O of the guaiacyl ring & 1269 \\
C-C and C-H stretching & 1215 \\
Aromatic C-H in-plane deformation in the guaiacyl ring & 1151 \\
Aromatic C-H deformation in the syringyl ring & 1116 \\
Aromatic C-H in-plane deformation & 1033 \\
\hline
\end{tabular}

\subsection{Effect of the Catalyst Content on the Physicochemical Properties of the UF Resin}

Fig. 2 shows that the $\mathrm{pH}$ value of the synthesized UF resin decreases by increasing the MA-HL and MAIL content from $0 \%$ to $3 \%$. Fig. 2 shows that the decrease of the $\mathrm{pH}$ value is initially very rapid, and that the slope of the curve then becomes less sharp with an increasing catalyst content. The acid groups grafted into lignin can catalyze the curing process of the UF resin. The effect of MA-HL and MA-IL on curing of the UF resin is to release $\mathrm{H}^{+}$and with the increasing $\mathrm{H}^{+}$concentration in the system, the rate of $\mathrm{H}^{+}$release probably is retarded. Thus, the $\mathrm{pH}$ decreases quickly in the beginning and then more slowly (Fig. 2). Based on the results obtained, the UF resin with MA-IL had lower $\mathrm{pH}$ compared to those with $\mathrm{NH}_{4} \mathrm{CL}$ and MA-HL at constant level, respectively. This indicates that a higher $\mathrm{H}^{+}$level can be obtained by addition of MA-IL rather than other catalysts used for UF resins.

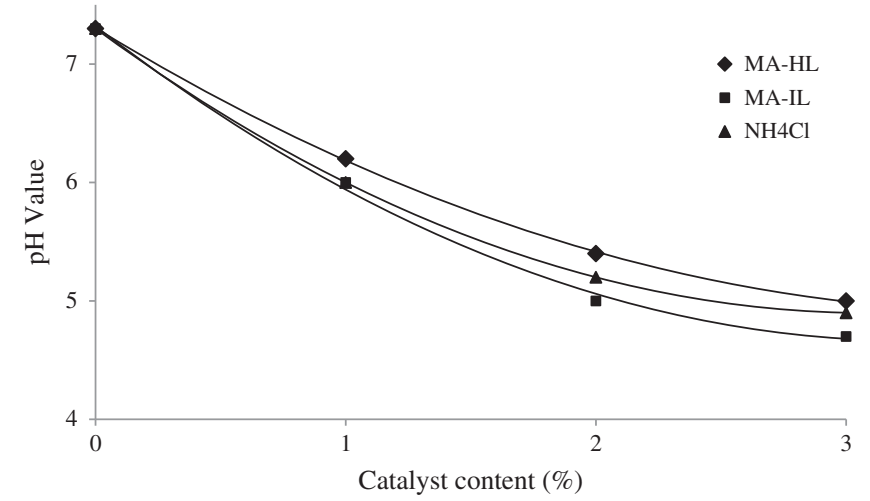

Figure 2: Effect of catalysts type on $\mathrm{pH}$ value of synthesized resin 


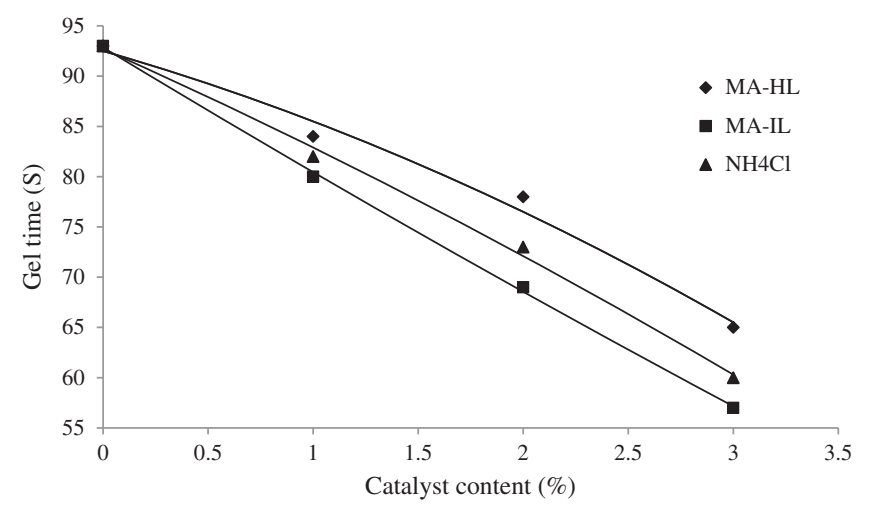

Figure 3: Effect of catalysts type on gelation time of synthesized resin

The effect of the MA-HL and MA-IL content on the gel time of a UF resin is shown in Fig. 3. It can be seen that increasing both catalysts from $1 \%$ to $3 \%$ significantly shortens the gel time of UF resins. The resins with 3\% MA-IL had 12\% faster gelation time compared to the UF resin with MA-HL at equal level. It is obvious that stronger acidity can result in a faster curing and cross-linking rate of the UF resin. Hence, the faster gelation time of the UF resin with MA-IL compared to that with MA-HL as catalyst is surely related to the difference in $\mathrm{pH}$. The results also indicate that the UF resin with MA-IL has a gel time shorter than that with $\mathrm{NH}_{4} \mathrm{Cl}$ at equal level. Thus, it the use of MA-IL as catalyst can further accelerates the rate of crosslinking. Xing et al. [19] indicated that the gel time of the UF resin obviously decreased with increasing catalyst content and decreasing $\mathrm{pH}$.

The physicochemical test results also indicated that increasing all types of catalysts from $1 \%$ to $3 \mathrm{wt} \%$ progressively increased the viscosity of the UF resin. UF resins with MA-HL had lower viscosity compared to those one with MA-IL which is probably related to the more rapid reaction and higher level of crosslinking with the ionic liquid solution (Fig. 4). The control resin with $\mathrm{NH}_{4} \mathrm{Cl}$ had the lowest viscosity among all the synthesized resins.

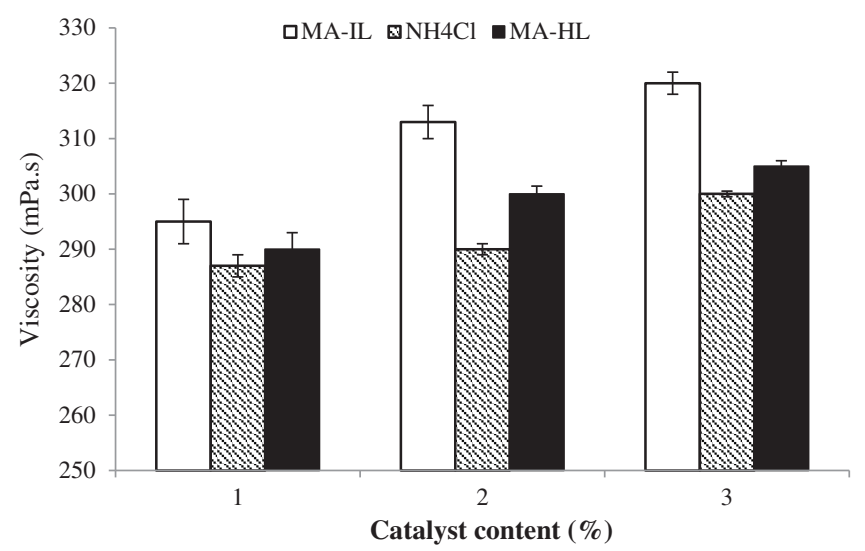

Figure 4: Influence of catalysts type on the viscosity of synthesized urea-formaldehyde resin

\subsection{DSC Analysis}

The influence of $2 \mathrm{wt} \% \mathrm{MA}-\mathrm{HL}, \mathrm{MA}-\mathrm{IL}$ and $\mathrm{NH}_{4} \mathrm{Cl}$ on the thermal curing behavior of UF resins was investigated by DSC. It can be seen that the curing process of the synthesized UF resin with all catalysts is an exothermic reaction (Fig. 5). As shown in Fig. 5, all catalysts have different effects on the exothermic peaks 
of the UF resin. For the UF resin with $\mathrm{NH}_{4} \mathrm{Cl}$, the peak of temperature (Tpeak) was about $110^{\circ} \mathrm{C}$ while those one with MA-HL was $100^{\circ} \mathrm{C}$. Based on the findings of this research, the peak temperature of the UF resin with MA-IL was $90^{\circ} \mathrm{C}$ which was lower than $\mathrm{MA}-\mathrm{HL}$ and $\mathrm{NH}_{4} \mathrm{Cl}$, respectively. The lower peak temperature of the UF resin containing the MA-IL catalyst compared to those with MA-HL indicated that the polyacids prepared from ionic liquid can further accelerates the hardening of a UF resin compared to those prepared with DMSO as a solution, and decrease further the energy of activation of curing of such a system. Previous studies indicated that ionic liquid can also better modify lignin structures compared to glyoxal resulting in higher reactivity of IL-treated lignin in the esterification process [11]. DSC results showing that the enthalpy of the cure reaction $(\Delta \mathrm{H})$ of the UF resin containing MA-IL was lower than that of MAHL, which suggested better thermal stability of the UF resin cured by ionic liquid. It also indicated that the addition of MA-IL to the UF resin does decrease further the energy of activation of the curing reaction compared to MA-HL. For commercial applications, the combination of low heat reaction and fast curing rate is desirable, so obviously the UF resin with MA-IL appears to be an ideal choice.

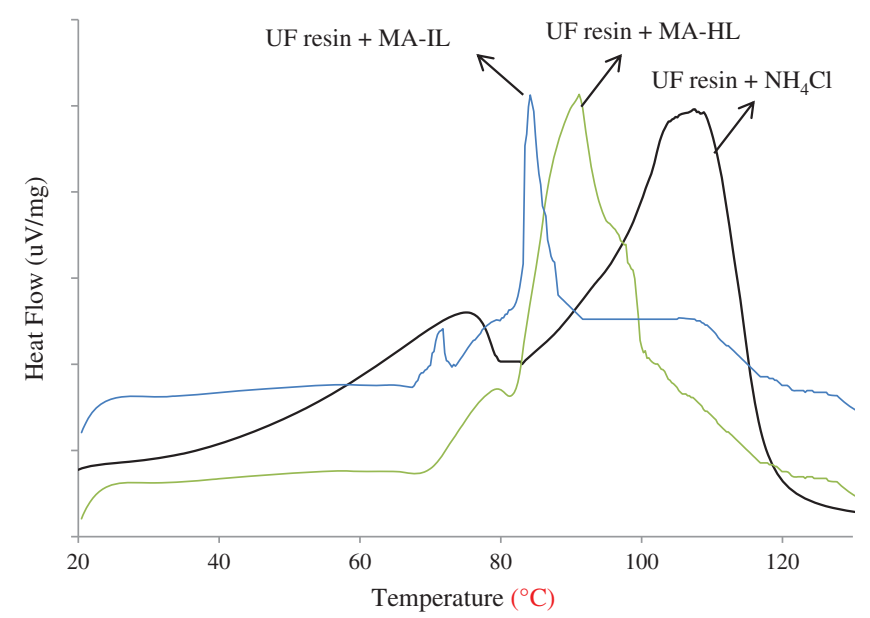

Figure 5: DSC curve of UF resin with MA-HL, MA-IL and $\mathrm{NH}_{4} \mathrm{Cl}$

\subsection{Properties of Panels Prepared}

The shear strength and corresponding wood failure percentages of the panels prepared are shown in Tab. 2. According to Tab. 2, the shear strengths and wood failure percentages of the panels manufactured using the resins increases with increasing additions of catalysts from $0 \%$ to $3 \%$. In addition to the enhanced catalytic performance, the higher amount of lignin might behave as a filler to efficiently improve shear strength [5]. In the plywood bonded with UF-lignin based catalyst, the highest shear strength $(2.7 \mathrm{MPa})$ and wood failure percentage (100\%) belonged to the UF resin containing 3\% MA-IL whereas the UF resin with 1\% MA-HL exhibited the lowest value strength $(1.95 \mathrm{MPa})$ and wood failure percentage (80\%), respectively. The higher shear strength of the panels made from UF resin with MA-IL rather than those one with MA-HL can be attributed to the better performance of the ionic liquid in esterifying lignin compared to other materials [10]. Lu et al. [10] indicating that ionic liquids function not only as good solvents but also as high performance catalysts for lignin esterification. Based on the FTIR analysis, more carboxyl groups $(\mathrm{COOH})$ can be formed in lignin after esterification by IL compared to DMSO. Husson et al. [11] indicated that the chemical structure of the lignin can be better modified by ionic liquids than glyoxal. IL may cause cleavage of secondary and weak ether linkages of the lignin macromolecule thereby reducing its molecular weight and polydispersity [16]. Hossian et al. [20] showed that the anion of ionic liquids undergoes nucleophilic attack or catalyzes the cleavage of the $b$-O- 4 lignin 
linkages, thus reducing its average molecular weight and the polydispersity. Hence, the potential reactivity of lignin modified by ionic liquid is significantly higher than that reacted with glyoxal which can have an influence on the catalyst performance on the resin. The higher shear strength and wood failure percentages of the panels bonded with the UF resin catalyzed with ionic liquids can also be attributed to higher heat conductivity of the ionic liquid compared to DMSO. Better heat transfer to the core of panels causes better polymerization of the resin in the board. The results also showed that panels with $3 \mathrm{wt} \%$ MA-HL and MA-IL catalyst presented higher shear strength and wood failure percentage than those that used ammonium chloride $\left(\mathrm{NH}_{4} \mathrm{Cl}\right)$ as a catalyst. This is possibly also due to the larger voids which are produced after resin shrinkages or evaporation of HCL in the UF resin structures under hot-pressing condition [21]. These voids in the glue line can reduce the mechanical strength of the resin as well as the shear strength of the panels bonded with it. Moreover, the increasing of the acidity of the curing agent leads to an increase in viscosity and complete condensation of the UF resin, finally enhancing the prepress properties of the UF resin containing the lignin based catalyst [22]. Conversely, due to the condensation improvement of the UF resin by adding MA-HL and MA-IL, the cured polymer network formed yields a higher mechanical interlocking strength between adhesive and veneer [23].

Table 2: The properties of the plywood panels made from synthesized resins

\begin{tabular}{llllll}
\hline Adhesive type & $\begin{array}{l}\text { Shear } \\
\text { strength } \\
(\mathrm{MPa})\end{array}$ & $\begin{array}{l}\text { Wood } \\
\text { failure } \\
(\%)\end{array}$ & $\begin{array}{l}\text { Water } \\
\text { absorption } \\
(\%)\end{array}$ & $\begin{array}{l}\text { Thickness } \\
\text { swelling } \\
(\%)\end{array}$ & $\begin{array}{l}\text { Formaldehyde } \\
\text { emission } \\
(\mathrm{mg} / 100 \mathrm{~g})\end{array}$ \\
\hline $\mathrm{UF}+2 \% \mathrm{NH}_{4} \mathrm{Cl}$ & $2.19 \pm 0.08$ & 100 & $49 \pm 2.2$ & $22 \pm 1$ & $4.3 \pm 0.1$ \\
$\mathrm{UF}+1 \% \mathrm{MA}-\mathrm{HL}$ & $1.95 \pm 0.03$ & 80 & $42 \pm 1.2$ & $20 \pm 0.8$ & $3.8 \pm 0.2$ \\
$\mathrm{UF}+2 \% \mathrm{MA}-\mathrm{HL}$ & $2.3 \pm 0.02$ & 95 & $37 \pm 1.3$ & $17 \pm 0.2$ & $3.7 \pm 0.2$ \\
$\mathrm{UF}+3 \% \mathrm{MA}-\mathrm{HL}$ & $2.4 \pm 0.03$ & 100 & $31 \pm 1.2$ & $16 \pm 0.4$ & $3.4 \pm 0.1$ \\
$\mathrm{UF}+1 \% \mathrm{MA}-\mathrm{IL}$ & $2.2 \pm 0.03$ & 85 & $38 \pm 1$ & $18 \pm 0.3$ & $3.6 \pm 0.3$ \\
$\mathrm{UF}+2 \% \mathrm{MA}-\mathrm{IL}$ & $2.5 \pm 0.01$ & 100 & $34 \pm 1.2$ & $15 \pm 0.2$ & $3.2 \pm 0.4$ \\
$\mathrm{UF}+3 \% \mathrm{MA}-\mathrm{IL}$ & $2.7 \pm 0.03$ & 100 & $28 \pm 0.8$ & $12 \pm 0.7$ & $3.1 \pm 0.4$ \\
\hline
\end{tabular}

Note: Means with different letters within the column are significantly different $(p<0.05)$.

Short-term (24 h) water absorption and thickness swelling of the panels prepared are presented in Tab. 2. It can be seen that the panels prepared with $\mathrm{NH}_{4} \mathrm{Cl}$ exhibited the highest water absorption (49\%) and thickness swelling (22\%) while the panels made from UF resin with 3\% MA-IL had the lowest water absorption (28\%) and thickness swelling (12\%), respectively. These results also show that lower water absorption and thickness swelling can be achieved by increasing the MA-HL and MA-IL proportion from $0 \%$ to 3\%. Based on these findings, the panels made from UF resin and MA-IL had higher dimensional stability compared to those with MA-HL at a constant level of catalyst used. This is probably due to the higher bonding strength of a UF resin with MA-IL compared to that of MA-HL. The higher level of crosslinks that appear to form after addition of MA-IL in the UF resin can also improve the dimensional stability of the panels. Higher water absorption and thickness swelling of the panels prepared with $\mathrm{NH}_{4} \mathrm{Cl}$ compared to those containing MA-IL and MA-HL can be explained by the evaporation of $\mathrm{HCl}$ during hot-pressing, this producing a greater porosity in the glue line which forms pores in the structure more accessible to water molecules [20]. The hydrophobicity of lignin also increases the water resistance of UF resin with a lignin-based catalysts compared on that catalyzed by $\mathrm{NH}_{4} \mathrm{Cl}$.

Formaldehyde is a major harmful substance in UF resins bonded plywood. The formaldehyde emission from the panels made from the synthesized resins is shown in Tab. 2. The subsequent formaldehyde emission 
from the panels in service also decreases if the proportion of a maleated lignins catalyst is increased in the UF resin. The acidic component can catalyze the curing process and enhance the level of condensation, this contributing furthermore to form more compact three-dimensionally crosslinked networks which can prevent or at least obstruct formaldehyde being emitted. The residual reactive sites in the lignin structure could also potentially react with formaldehyde to decrease its emission [5]. The lower formaldehyde emission of the panels with MA-IL can be explained by the fact that this type of catalyst can form more cross-links than that of catalyzed with MA-HL. This is due to most of the free formaldehyde available in the UF resin being able to further react with residual unreacted sites of lignin. Based on the results of this research work, the highest formaldehyde emission $(4.3 \mathrm{mg} / 100 \mathrm{~g})$ can be observed for the panels bonded with the control UF resin catalyzed with $\mathrm{NH}_{4} \mathrm{Cl}$, while the lowest value $(3.1 \mathrm{mg} / 100 \mathrm{~g})$ is observed for the panels with UF resin catalyzed with 3\% MA-IL. As regards the low dimensional stability and high formaldehyde emission being the main problems associated to panels bonded with UF resins, the addition of MA-IL as catalyst can almost solve these problems.

\section{Conclusion}

In this work, synthesis of lignin-based polyacid with ionic liquid as a catalyst for urea-formaldehyde resin and its effect on physical and mechanical properties of the plywood panels was investigated. The following conclusions can be drawn from the results:

- The FTIR analysis indicated that the $\mathrm{COOH}, \mathrm{O}-\mathrm{H}$ and $\mathrm{C}-\mathrm{O}$ bonds in IL-treated lignin are higher than in hydroxymethylated lignin.

- The gel time of UF resins is shortened by increasing the MA-IL content from $1 \%$ to $3 \%$. The gelation time of the UF resin with MA-IL was also faster than with MA-HL.

- DSC analysis indicated that the UF resins with MA-IL had a lower peak temperature than those with MA-HL and $\mathrm{NH}_{4} \mathrm{Cl}$, respectively, hence a lower energy of activation of curing.

- The plywood panels prepared with MA-IL had higher shear strength and dimensional stability compared to those made from UF resin containing MA- $\mathrm{HL}$ and $\mathrm{NH}_{4} \mathrm{Cl}$, respectively.

- The panels made from UF resins catalyzed with MA-IL yielded panels presenting the lowest formaldehyde emission.

Funding Statement: The authors received no specific funding for this study.

Conflicts of Interest: The authors declare that they have no conflicts of interest to report regarding the present study.

\section{References}

1. Wu, Z., Liang, J., Lei, H., Zhang, B., Xi, X. et al. (2021). Study on the soy protein-based adhesive cross-linked by glyoxal. Journal of Renewable Materials, 9(2), 205-208. DOI 10.32604/jrm.2021.013655.

2. Younesi-Kordkheili, H., Pizzi, A. (2016). Acid ionic liquids as a new hardener in urea-glyoxal adhesive resins. Polymers, 8(3), 1-14. DOI 10.3390/polym8030057.

3. Sun, Q. N., Hse, C. Y., Shupe, T. F. (2014). Effect of different catalysts on urea-formaldehyde resin synthesis. Journal of Applied Polymer Science, 131(16), 1-7. DOI 10.1002/app.40644.

4. Xing, C., Zhang, S. Y., Deng, J., Wang, S. (2007). Urea-formaldehyde-resin gel time as affected by the pH value, solid content, and catalyst. Journal of Applied Polymer Science, 103, 1566-1569. DOI 10.1002/(ISSN)1097-4628.

5. Costa, N. A. D., Pereira, J., Martins, J. M., Joao, F., Cruz, P. et al. (2012). Alternative to latent catalysts for curing UF resins used in the production of low formaldehyde emission wood-based panels. International Journal of Adhesion and Adhesives, 33, 56-60. DOI 10.1016/j.jiadhadh.2011.11.003. 
6. Gao, S., Liu, Y., Wang, C., Chu, F., Xu, F. et al. (2020). Synthesis of lignin-based polyacid catalyst and its utilization to improve water resistance of urea-formaldehyde resins. Polymers, 12(1), 2-12. DOI 10.3390/ polym 12010175 .

7. Younesi-Kordkheili, H., Pizzi, A. (2021). Maleated lignin coreaction with phenol-formaldehyde resins for improved wood adhesives performance. International Journal of Adhesion and Adhesives (in Press).

8. Jiang, X., Liu, G., Du, X., Hu, Z., Chang, H. M. et al. (2018). Phenolation to improve lignin reactivity toward thermosets application. ACS Sustainable. Chemical Engineering, 6(4), 5504-5512. DOI 10.1021/ acssuschemeng.8b00369.

9. Goncalves, A. R., Benar, P. (2001). Hydroxymethylation and oxidation of organosolv lignins and utilization of the products. Bioresource Technology, 79(2), 103-111. DOI 10.1016/S0960-8524(01)00056-6.

10. Lu, J., Yan, F., Texter, J. (2009). Advanced applications of ionic liquids in polymer science. Progress in Polymer Science, 34(5), 431-448. DOI 10.1016/j.progpolymsci.2008.12.001.

11. Husson, E., Hulin, L., Hadad, C., Boughanmi, C., Stevanovic, T. et al. (2019). Acidic ionic liquid as both solvent and catalyst for fast chemical esterification of industrial lignins: Performances and regioselectivity. Frontiers Chemistry, 7, 1-13. DOI 10.3389/fchem.2019.00578.

12. Li, L., Wu, Z., Xi, X., Liu, B., Cao, Y. et al. (2021). A bifunctional brønsted acidic deep eutectic solvent to dissolve and catalyze the depolymerization of alkali lignin. Journal of Renewable Materials, 9(2), 1-18. DOI 10.32604/ jrm.2021.012099.

13. Bernardo, J. R., Gírio, F. M., Łukasik, R. M. (2019). The effect of the chemical character of ionic liquids on biomass pre-treatment and posterior enzymatic hydrolysis. Molecules, 24(4), 808. DOI 10.3390/ molecules24040808.

14. Gao, Z., Wang, X. M., Wan, H., Liu, Y. (2007). Curing characteristics of urea-formaldehyde resin in the presence of various amounts of wood extracts and catalysts. Journal of Applied Polymer Science, 107, 1555-1562. DOI 10.1002/(ISSN)1097-4628.

15. Navarrete, P., Pizzi, A., Tapin-Lingua, S., Benjelloun-Mlayah, B., Pasch, H. et al. (2011). Wood panel adhesives from low molecular mass lignin and tannin without synthetic resins. Journal of Adhesion Science and Technology, 26(10-11), 1667-1684. DOI 10.1163/156856111X618489.

16. Qu, Y., Luo, H., Xu, H. (2015). Comparison on structural modification of industrial lignin by wet ball milling and ionic liquid pretreatment. Biotechnology Reports, 6, 1-7. DOI 10.1016/j.btre.2014.12.011.

17. Binder, J. B., Gray, M. J., White, J. F., Zhang, Z. C., Holladay, J. E. (2009). Holladay reactions of lignin model compounds in ionic liquids. Biomass and Bioenergy, 33(9), 1122-1130. DOI 10.1016/j.biombioe.2009.03.006.

18. Younesi-Kordkheili, H., Pizzi, A., Honarbakhsh-Raouf, A., Nemati, F. (2017). The effect of soda bagasse lignin modified by ionic liquids on properties of the urea-formaldehyde resin as a wood adhesive. Journal of Adhesion, 93(11), 914-925. DOI 10.1080/00218464.2016.1188284.

19. Xing, C., Zhang, S. Y., Deng, J., Wang, S. (2007). Urea-formaldehyde-resin gel time as affected by the pH value, solid content, and catalyst. Journal of Applied Polymer Science, 103, 1566-1569. DOI 10.1002/(ISSN)1097-4628.

20. Hossain, M. M., Aldous, L. (2012). Ionic liquids for lignin processing: Dissolution, isolation, and conversion. Australian Journal of Chemistry, 65(11), 1465-1477. DOI 10.1071/CH12324.

21. Kardos, J. L., Dudu, K., Dave, R. (1986). Void growth and resin transport during processing of thermosettingmatrix composites. Advances in Polymer Science, 80, 101-123. DOI 10.1007/3-540-16423-5.

22. No, B. Y., Kim, M. G. (2004). Syntheses and properties of low-level melamine-modified urea-melamineformaldehyde resins. Journal of Applied Polymer Science, 93, 2559-2569. DOI 10.1002/(ISSN)1097-4628.

23. Shahid, S. A., Ali, M., Zafar, Z. I. (2014). Characterization of phenol formaldehyde resins modified with crude bio-oil prepared from Ziziphus mauritiana endocarps. Bioresources, 9(3), 5362-5384. DOI 10.15376/biores.9.3.5362-5384. 